\title{
YÜKSEK FIRIN CÜRUFU KATKILI SILIINDİRLE SIKIŞTIRILMIŞ BETONLARIN ÖZELLİKLERİ
}

\author{
1İsmail KILIÇ(iD) , 2 Saadet Gökçe GÖK \\ 1,2Kırklareli Üniversitesi, Mühendislik Fakültesi, İnşaat Mühendisliği Bölümü, Kırklareli, TÜRKIYYE \\ ${ }^{1}$ ismail.kilic@klu.edu.tr, ${ }^{2}$ saadet.gokce.gok@klu.edu.tr
}

(Geliş/Received: 26.09.2021; Kabul/Accepted in Revised Form: 22.11.2021)

ÖZ: Bu çalışmada, öğütülmüş yüksek fırın cürufu ikamesinin silindirle sıkıştırılmış betonun fiziksel ve mekanik özelliklerine etkisinin araştırılması amaçlanmıştır. Deneysel çalışmada, Portland çimentosunun yerine ağırlıkça \%10, \%20 ve \%30 oranlarında öğütülmüş yüksek fırın cürufu kullanılarak silindirle sıkıştırılmış beton üretimi gerçekleştirilmiştir. Üretilen silindirle sıkıştırılmış beton numunelerinin sıkıştırılabilme yüzdesi, birim hacim ağırlık, ultrases geçiş hızı, dinamik elastisite modülü, su emme, 3 ve 28 günlük beton basınç dayanımı değerleri tespit edilmiştir. Silindirle sıkıştırılmış betonlarda yüksek fırın cürufu kullanımıyla işlenebilirlik olumlu etkilenmiş, sıkıştırılabilme yüzdeleri artmıştır. Yüksek fırın cürufu ikamesi 3 günlük beton basınç dayanımlarında azalmaya neden olurken 28 günlük beton basınç dayanımlarında artış sağlamıştır.

Anahtar Kelimeler: Fiziksel özellikler, Mekanik özellikler, Yüksek firın cürufu, Puzolan, Sıkıştırılabilme yüzdesi, Silindirle sıkıştırılmıı̧ beton

\section{The Properties of Roller Compacted Concretes Incorporating Blast Furnace Slag}

\begin{abstract}
In this study, it was aimed to investigate the effect of ground blast furnace slag replacement on the physical and mechanical properties of roller compacted concretes. In the experimental study, roller compacted concretes were produced by using ground blast furnace slag as $10 \%, 20 \%$ and $30 \%$ of the weight of portland cement. The percentage of compactibility, unit weight, ultrasonic pulse velocity, dynamic modulus of elasticity, water absorption, and concrete compressive strength at the ages of 3 and 28 days were determined. With the use of blast furnace slag in roller compacted concretes, workability of concrete was positively affected and the percentages of compactibility increased. The replacement of blast furnace slag caused a decrease in 3-d concrete compressive strength, while it increased the $28-\mathrm{d}$ concrete compressive strength.
\end{abstract}

Key Words: Physical properties, Mechanical properties, Blast furnace slag, Pozzolan, Compactibility percentage, Roller compacted concrete

\section{GİRİŞ (INTRODUCTION)}

Silindirle sıkıştırılmış betonlarda (SSB) mekanik özellikler, normal betonlarda olduğu gibi, su/bağlayıcı oranı, çimento dozajı, kullanılan mineral katkı ve agrega bileşiminden etkilenmektedir (Yazıcı, 2008; Kılıç ve Gök, 2021a). Silindirle sıkıştırılmış betonlar, kuru kıvamlı betonlar olup nihai şekline ulaşabilmek için sıkıştııılmaya ihtiyaç duyar, sıkıştırma makinesinin zorlanmaması ve sıkıştırma enerjisinin azaltılabilmesi için bu betonlarda belirli bir kıvamın sağlanması gerekir (Chhorn ve Lee, 2017). Silindirle sıkıştırılmış betonlarda geleneksel betona göre çok daha kuru kıvamda çalışılması, taze beton 
özelliklerinde farklılıklar meydana getirmekte, geleneksel beton üretiminde kullanılan katkılar bu betonlarda da kullanılabilmesine rağmen katkı dozajlarında değişikliğe gitmek gerekmektedir.

Betonun işlenebilirliğinin, kohezyon, sıkıştırılabilirlik, ayrışma direnci, işlenebilirliğin korunması, su kesme ve kıvamdan oluştuğu düşünülmektedir; belirli bir karışım için işlenebilirlikteki gelişme, bu bileşenlerin yanı sıra, iç sürtünme açısı, betondaki hava miktarı, katkı tipi ve dozajına da bağlı olarak değişmektedir (Hazaree ve diğ., 2013; Hazaree, 2010). Silindirle sıkıştırılmış betonlar, Abrams kanunundaki sapmalarla gösterildiği üzere, mekanik dayanım açısından anormal davranış göstermekte olup su/bağlayıcı oranının genel somut davranışı ve eğilimleri açılamak için kapsamlı bir parametre olmadığı tartışılmaktadır (Hazaree, 2010).

Silindirle sıkıştırılmış betonlarda uçucu kül başta olmak üzere, silis dumanı, pirinç kabuğu külü gibi çeşitli mineral katkılar kullanılabildiği gibi kimyasal katkılar ve liflerde kullanılabilmektedir (Harrington ve diğg., 2010; K1lıç ve Gök, 2021b; Modarres ve Hosseini, 2014; Şengün ve diğ., 2017; TÇMB, 2018; Yetim ve Yılmaz, 2019; Shen ve diğ., 2020; Kılıç ve Gök, 2021c; Hashemi ve diğ., 2020). Silindirle sıkıştırılmış betonlarda bağlayıcı olarak yüksek fırın cürufu, uçucu kül ve silis dumanı kullanımı, işlenebilirliği ve erken yaş mukavemetini önemli derecede etkilemektedir. SSB karışımlarında, ayrışmaya karşı direncinin incelenmesi önem kazanmakta, karışım performansını iyileştirmek üzere geleneksel betonlarda kullanılan kimyasal katkılar, çelik ya da polipropilen lifler kullanılabilmektedir (Mardani ve diğ., 2020). Yüksek fırın cürufu ve uçucu kül kullanımı silindirle sıkıştırılmış beton özelliklerini iyileştirmekte, ekonomik ve çevresel açıdan fayda sağlamaktadır (Pektaş, 2015). Bu katkıların dışında, katyonik asfalt emülsiyonunun silindirle sıkıştırılmış betonlarda katkı olarak kullanımına dair çalışmalar da yapılmıştır (Dareyni ve diğ., 2018). Beton Yollar Teknik Şartnamesi'ne (KGM, 2016) göre, beton yol imalatında hava sürükleyici, su azaltıcı, yüksek oranda su azaltıcı, priz geciktirici katkılar ve uzun işlenebilirlik katkıları kullanılmaktadır. Silindirle sıkıştırılmış beton uygulamalarında katkı ile üretim şart olmamakla birlikte katkı kullanımı, taze ve/veya sertleşmiş beton özelliklerini iyileştirmek üzere tercih edilmektedir (Engin ve diğ., 2019).

Öğütülmüş yüksek fırın cürufu, tek başına bağlayıcılığı çok az olan, ortamda kireç ve nem varlığında bağlayıcılık kazanan bir malzemedir. Hidratasyonu çok yavaş olduğu için aktivasyona ihtiyaç duyar, bu nedenle sıklıkla çimento ile birlikte kullanılmaktadır. Yüksek fırın cürufu, demir-çelik üretiminde elde edilen bir atık üründür. Yüksek fırın cürufunun beton üretiminde yeniden değerlendirilmesi, ekonomik ve çevresel açıdan fayda sağladığı gibi betonda geçirimsizliğin artııılması, hidratasyon ısısının ve boşluk oranının azaltılmasının yanı sıra ilerleyen yaşlarda beton basınç dayanımının artmasına da katkıda bulunarak beton özelliklerini iyileştirmektedir. Yüksek fırınlardan elde edilen cüruf, soğutulduktan sonra çimento inceliğinde ögütülür ve puzolan olarak kullanılır. Öğütülmemiş hali, yollarda, alt temelde, dolgu malzemesi olarak kullanılabilmektedir.

Ögütülmüş yüksek fırın cürufu, demir-çelik üretim tesisleri çevresinde kurulu cüruf üreticilerinden temin edilebilmektedir, Türkiye özelinde düşünüldüğünde, bu malzeme diğer pek çok puzolana göre kolay erişilebilir durumdadır. Demir-çelik üretiminde açığa çıkan bir atığın beton içerisinde yeniden değerlendirilmesiyle, bu atığın bertaraf edilmesine yardımcı olunmakta, çevreye duyarlılık ve ekonomik imalat konularında fayda sağlanırken sürdürülebilir bir beton üretimine katkıda bulunulmaktadır. Bununla birlikte, yüksek fırın cürufunun silis dumanı kadar ince bir malzeme olmayışı, betonda su ihtiyacı, işlenebilirlik ve buna bağlı olarak beton özelliklerinin iyileşmesi konularında avantaj sağlamakta, bu malzeme ile çalışmayı kolaylaştırmaktadır.

Cürufun yapı malzemesi olarak kullanılabilmesinde belirleyici faktör malzemenin reaktivitesi olup yapılan soğutma işlemi malzeme özelliklerini etkilemektedir. Yüksek fırın cürufu, çoğunlukla kalsiyum alümina silikatlardan oluşmaktadır. Cürufun camsı yapısı ve yüksek reaktivitesi, hidrolik bağlayıcı olarak kullanılması için temel gereksinimler olup malzemenin suda hızlı soğutulması ile sağlanır. Öğütme işleminden önce, hidrolik bağlayıcının imalatında kullanıldığında, cüruf $0,2 \mathrm{~mm}-8 \mathrm{~mm}$ çapında nehir kumuna benzeyen bir tane boyutuna ve görünüme sahiptir (Albuquerque ve diğ., 2011). Yalnızca Portland çimentosu içeren beton ile kıyaslandığında yüksek fırın cüruflu beton, daha yüksek oranda kalsiyum silikat hidrat $(\mathrm{CSH})$ ve daha düşük oranda serbest kireç içerir; $\mathrm{CSH}$ içeriğinin artması beton basınç 
dayanımını arttırmakta iken serbest kirecin nihai dayanıma etkisi yoktur, bu şekilde cüruf kullanımıyla betonun mekanik özellikleri iyileştirilebilmektedir (Topçu, 2013).

Yol inşaatı, baraj inşaatı gibi çeşitli inşaat alanlarında silindirle sıkıştırılmış betonun dikkate değer gelişimi, araştırmacıları farklı değişkenlerin silindirle sıkıştırılmış beton özellikleri üzerindeki etkisini incelemeye yöneltmiştir. Karimpour (2010), çalışmasında, malzemelerin karıştırılmasının başlangıcından sıkıştırılmasının bitimine kadar geçen sürenin SSB özelliklerini etkileyen parametrelerden biri olduğunu ifade etmiş, karıştırma ve sıkıştırma arasındaki zaman aralığının değiştirilmesinin geleneksel beton ve öğütülmüş yüksek fırın cürufu içeren silindirle sıkıştırılmış betonların mekanik özellikleri üzerindeki etkisini incelemiştir. Sıkıştırmadaki gecikme arttıkça, geleneksel beton özelliklerindeki kaybın arttığını, ancak çimento esaslı malzemenin bir bölümü olarak öğütülmüş yüksek fırın cürufu kullanıldığında, sıkıştırmada daha fazla gecikmenin beton özelliklerini olumsuz etkilemediğini, hatta bazı koşullarda, beton basınç dayanımını, geçirimliliğini, absorpsiyonunu ve adsorpsiyonunu iyileştirdiğini belirtmiştir (Karimpour, 2010). Başka bir çalı̧̧mada, öğütülmüş yüksek fırın cürufunun SSB kaplamaların dayanıklılığı üzerindeki etkileri incelenmiş, betonun su emme, geçirimlilik ve donma-çözülme döngülerine karşı dayanıklılığı gibi özellikleri dikkate alınmıştır (Aghaeipour ve Madhkhan, 2017). Çalışmanın neticesinde, betonun maksimum sıkıştırmaya ulaşması için gereken su muhtevasının, artan cüruf içeriği ile arttığı görülmüş, çimentonun cürufla \%40 oranında değiştirilmesinin porozite, su emme ve geçirimliliğin azalmasını sağladığı ifade edilmiştir (Aghaeipour ve Madhkhan, 2017).

Bu çalışmada, öğütülmüş yüksek fırın cürufu ikamesinin silindirle sıkıştırılmış betonun fiziksel ve mekanik özelliklerine etkisi araştırılmıştır. Portland çimentosunun yerine ağırlıkça \%10, \%20 ve \%30 oranlarında ögütülmüş yüksek fırın cürufu kullanılarak silindirle sıkıştırılmış beton üretimi gerçekleştirilmiştir. Üretilen SSB numunelerinin sıkıştırılabilme yüzdesi, birim hacim ağırlık, su emme, ultrases geçiş hızı, dinamik elastisite modülü, 3 ve 28 günlük beton basınç dayanımı değerleri saptanmıştır.

\section{MALZEME VE YÖNTEMLER (MATERIALS AND METHODS)}

Silindirle sıkıştırılmış beton üretiminde, şehir şebeke suyu, kırmataş II, kırmataş I, taş tozu, doğal kum, CEM II/B-L 32,5 R Portland çimentosu ve öğütülmüş yüksek fırın cürufu kullanılmıştır. Agregaların özgül ağırlık tayininde TS EN 1097-6 (2013) standardı esas alınmıştır. Kullanılan dolomit kökenli kırmataş II, kırmataş I ve taş tozunun özgül ağırlığ 2,80, kumun özgül ağırlığı 2,75, çimentonun özgül ağırlığı 2,95, yüksek fırın cürufunun özgül ağırlığ 2,53'tür. Agregaların elek analizi TS EN 933-1'e (2012) uygun olarak yapılmış ve Çizelge 1'de verilmiştir. Portland çimentosunun fiziksel ve kimyasal özellikleri Çizelge 2'de verilmiştir.

Çizelge 1. Elek analizi

Table 1. Sieve analysis

\begin{tabular}{cccccc}
\hline $\begin{array}{c}\text { Elek Açıklı̆̆ } \\
(\mathrm{mm})\end{array}$ & $\begin{array}{c}\text { Kırmataş II } \\
(\% 20)\end{array}$ & $\begin{array}{c}\text { Kırmataş I } \\
(\% 35)\end{array}$ & $\begin{array}{c}\text { Taş Tozu } \\
(\% 15)\end{array}$ & $\begin{array}{c}\text { Doğal Kum } \\
(\% 30)\end{array}$ & $\begin{array}{c}\text { Karışım } \\
(\% 100)\end{array}$ \\
\hline 22,5 & 100,00 & 100,00 & 100,00 & 100,00 & 100,00 \\
16 & 47,12 & 100,00 & 100,00 & 100,00 & 86,78 \\
12,5 & 0,00 & 94,32 & 100,00 & 100,00 & 73,58 \\
9,5 & 0,00 & 79,29 & 100,00 & 100,00 & 69,82 \\
4 & 0,00 & 9,16 & 91,73 & 97,20 & 49,52 \\
2 & 0,00 & 0,00 & 87,45 & 93,62 & 45,27 \\
1 & 0,00 & 0,00 & 54,44 & 83,95 & 34,60 \\
0,5 & 0,00 & 0,00 & 28,21 & 52,68 & 20,22 \\
0,25 & 0,00 & 0,00 & 16,06 & 30,19 & 11,56 \\
0,125 & 0,00 & 0,00 & 8,03 & 3,68 & 2,93 \\
0,075 & 0,00 & 0,00 & 4,32 & 1,24 & 1,39 \\
\hline
\end{tabular}


Çizelge 2. Çimentonun fiziksel ve kimyasal özellikleri (Url-1, 2021)

Table 2. Physical and chemical properties of the cement (Url-1, 2021)

\begin{tabular}{cc} 
Özellikler & \\
\hline Priz Başlangıç (dakika) & $155 \pm 25$ \\
Priz Sonu (dakika) & $230 \pm 40$ \\
Özgül Ağırlık & $2,95 \pm 0,06$ \\
Hacim Genleşmesi(mm) & $1,0 \pm 1$ \\
Özgül Yüzey (cm²/g) & $4980 \pm 400$ \\
2 Günlük Dayanım (MPa) & $20,5 \pm 3$ \\
28 Günlük Dayanım (MPa) & $38,9 \pm 4$ \\
SO 3 & $2,80 \pm 0,35$ \\
MgO & $0,90 \pm 0,20$ \\
Kızdırma Kaybı & $13,10 \pm 3$ \\
Serbest Kireç & $1,80 \pm 0,6$ \\
\hline
\end{tabular}

Öğütülmüş yüksek fırın cürufu, çimento ağırlığının \%10'u, \%20'si ve \%30'u oranlarında ikame edilerek farklı karışımlar hazırlanmıştır. Beton karışım hesabı TS 802 (2016), taze betonda çökme deneyi TS EN 12350-2 (2019) standardına göre yapılmıştır. Üretilen karışımlar kuru kıvamda ve çökme değeri sıfır olacak şekilde tasarlanmıştır.

Ögütülmüş yüksek fırın cürufunun özellikleri Çizelge 3'te verilmiştir.

Çizelge 3. Yüksek fırın cürufunun özellikleri (Url-2, 2021) Table 3. The properties of blast furnace slag (Url-2,2021)

\begin{tabular}{cccc}
\multicolumn{4}{c}{ Table 3. The properties of blast furnace slag (Url-2, 2021) } \\
\hline Tipik Özellikler & & $\begin{array}{c}\text { Standart Değer } \\
\text { (TS EN 15167-1 2006) }\end{array}$ & $\begin{array}{c}\text { Yüksek Firın } \\
\text { Cürufu }\end{array}$ \\
\hline Aktivite, 7 gün & $\%$ & min. 10,0 & 50,0 \\
Aktivite, 28 gün & $\%$ & $42,5-62,5$ & 75,0 \\
Hacim Genleşmesi & $\mathrm{mm}$ & - & 1,0 \\
Özgül Yüzey & $\mathrm{cm}^{2} / \mathrm{g}$ & - & 4800 \\
$\mathrm{MgO}$ & $\%$ & maks. 18,0 & 7,0 \\
$\mathrm{~S}$ & $\%$ & maks. 2,0 & 0,75 \\
$\mathrm{SO} 3$ & $\%$ & maks. 2,50 & 0,15 \\
Klorür & $\%$ & maks. 0,1000 & 0,0100 \\
Kizdırma Kaybı & $\%$ & maks. 3,00 & 0,10 \\
Rutubet & $\%$ & maks. 1,00 & 0,10 \\
\hline
\end{tabular}

Silindirle sıkıştırılmış beton karışımları için $1 \mathrm{~m}^{3}$ hacimdeki malzeme miktarları Çizelge 4 'te verilmiştir. Karışım tasarımı, agregaların yüzey kuru suya doygun durumu dikkate alınarak yapılmıştır. Toplam agrega karışımının ağırlıkça \%20'si kırmataş II'den, \%35'i kırmataş I'den, \%15'i taş tozundan ve $\% 30$ 'u doğal kumdan oluşmaktadır. 
Çizelge 4. Beton karışım tasarımı $\left(1 \mathrm{~m}^{3}\right)$.

Table 4. Concrete mix design $\left(1 \mathrm{~m}^{3}\right)$

\begin{tabular}{ccccccccc}
\hline $\begin{array}{c}\text { Karışım } \\
\text { Kodu }\end{array}$ & Su/Bağlayıcı & $\begin{array}{c}\text { Su } \\
(\mathbf{k g})\end{array}$ & $\begin{array}{c}\text { Çimento } \\
(\mathbf{k g})\end{array}$ & $\begin{array}{c}\text { Yüksek } \\
\text { Firın } \\
\text { Cürufu } \\
\mathbf{( k g )}\end{array}$ & $\begin{array}{c}\text { Doğal } \\
\text { Kum } \\
(\mathbf{k g})\end{array}$ & $\begin{array}{c}\text { Taş } \\
\text { Tozu } \\
(\mathbf{k g})\end{array}$ & $\begin{array}{c}\text { Kırmataş } \\
\mathbf{I}(\mathbf{k g})\end{array}$ & $\begin{array}{c}\text { Kırmataş } \\
\text { II (kg) }\end{array}$ \\
\hline S0 & 0,34 & 102 & 300 & 0 & 657 & 334 & 780 & 446 \\
S10 & 0,34 & 102 & 270 & 30 & 657 & 334 & 780 & 446 \\
S20 & 0,34 & 102 & 240 & 60 & 657 & 334 & 780 & 446 \\
S30 & 0,34 & 102 & 210 & 90 & 657 & 334 & 780 & 446 \\
\hline
\end{tabular}

Silindirle sıkıştırılmış beton numunelerinin üretimi, ASTM C1435 (2020) standardına uygun olarak gerçekleştirilmiştir. Sıkıştırma işlemi, kalıp şekli ile uyumlu, özel üretilmiş başlıklar kullanılarak yapılmıştır. Standart küp numuneler, tek tabakada 15 saniye boyunca sıkıştırılmıştır. Birden fazla kademede yapılan sıkıştırma işlemlerinde soğuk derz oluşumu ile karşılaşıldığından, tek tabakada sıkıştırma yoluna gidilmiştir.

Numunelerdeki sıkıştırılabilme yüzdesi hesaplanırken, öncelikle $15 \mathrm{~cm} \times 15 \mathrm{~cm} \times 15 \mathrm{~cm}$ boyutlu küp kalıplar üst seviyesine kadar taze haldeki SSB ile doldurulmuş, tesviye edildikten sonra 15 saniye sıkıştırılmış ve sıkıştırma sonunda, kalıbın dört kenarının orta noktalarından içe doğru oluşan boşluk derinliği ölçülmüş̧ür (Şekil 1 ve Şekil 2). Dört noktadan ölçüm yapıldıktan sonra bu değerlerin aritmetik ortalamaları alınmış, belirlenen ortalama değer küp kalıbın iç kenar uzunluğuna oranlanarak SSB örneğinin sıkıştırılabilme yüzdesi tespit edilmiştir.

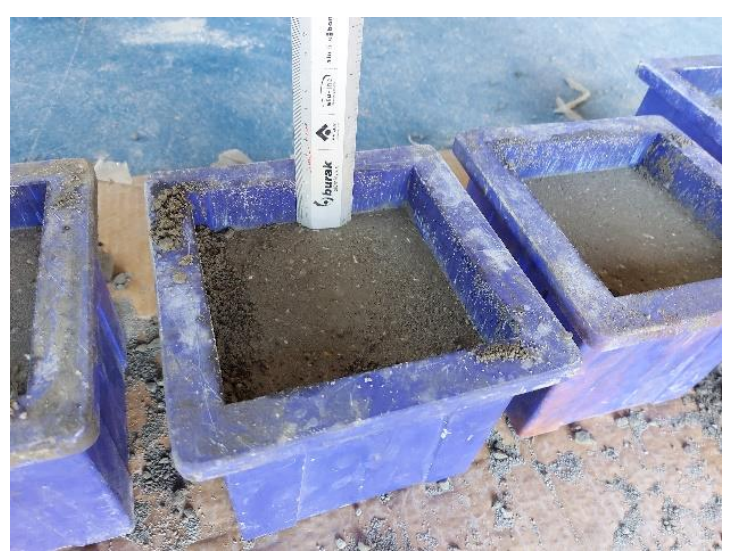

Şekil 1. Sıkıştırılabilme yüzdesi tespiti öncesi ölçüm

Figure 1. Measurement for detecting percentage of compactibility

Üretilmiş numuneler, üretimden bir gün sonra kalıptan çıkarılmış, deney zamanına kadar kür havuzunda, kirece doygun suda bekletilmiştir. 


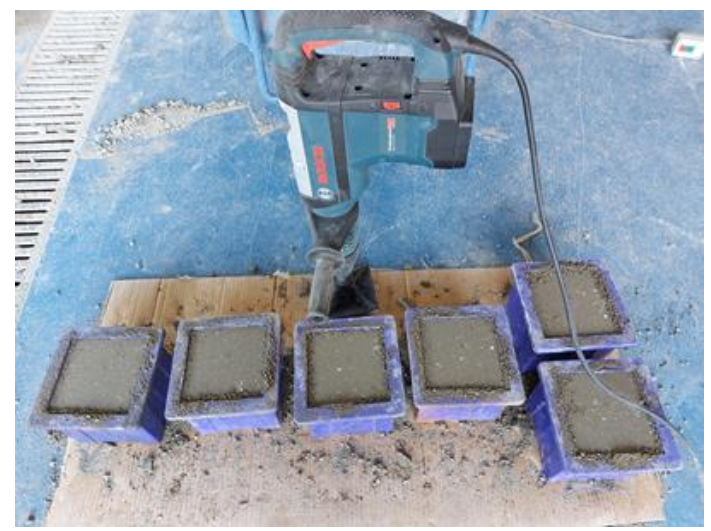

Şekil 2. Kalıplarda sıkıştırılmış SSB örnekleri

Figure 2. RCC specimens in molds

Silindirle sıkıştırılmış betonların basınç dayanımının belirlenmesinde, TS EN 12390-3 (2019) standardı esas alınarak 3 ve 28 günlük numuneler test edilmiştir. Yükleme hızı 0,602 MPa/s olarak alınmıştır. Her bir deney grubu için üçer numune test edilmiş olup ortalama değerler belirlenmiştir.

Silindirle sıkıştırılmış beton numunelerin toplam su emme yüzdeleri 28 günlük SSB numunelerinde, EN 772-11 (BSI, 2011) standardına göre belirlenmiştir. 48 saat boyunca etüvde kurutularak sabit ağırlığa gelen silindirle sıkıştırılmış beton numunelerin ağırlıkları kaydedilmiş, ardından bu numuneler 24 saat boyunca suda bekletilmiş ve su emme yüzdeleri hesaplanmıştır.

28 günlük SSB numunelerin ultrases geçiş hızı değerleri ASTM C597 (2016) standardına uygun olarak ölçülmüş ve dinamik elastisite modülü değerleri tespit edilmiştir.

Ultrases geçiş hızı ve dinamik elastisite modülünün elde edilmesinde Proceq marka Pundit PL-200 ultrasonik test cihazı kullanılmıştır. Bu deneyler için $15 \mathrm{~cm} \times 15 \mathrm{~cm} \times 15 \mathrm{~cm}$ boyutlu 28 günlük küp SSB numuneleri kullanılmıştır. Deney bulguları sunulurken her bir seriden üçer adet numune test edilerek ortalama değerler kullanılmıştır.

\section{BULGULAR VE TARTIŞMA (RESULTS AND DISCUSSION)}

Silindirle sıkıştırılmış beton numunelerin ortalama sıkıştırılabilme yüzdeleri Çizelge 5 'te verilmiştir.

Çizelge 5. Sıkıştırılabilme yüzdesi

Table 5. The percentage of compactibility

\begin{tabular}{cc}
\hline Karışım kodu & Sıkıştırılabilme yüzdesi (\%) \\
\hline S0 & 11,11 \\
S10 & 12,56 \\
S20 & 13,33 \\
S30 & 14,81 \\
\hline
\end{tabular}

Beton karışımında kullanılan öğütülmüş yüksek fırın cürufu miktarı arttıkça betonda işlenebilirlik iyileşmiş, sıkıştııılabilme yüzdelerinde artış meydana gelmiştir. Sıkıştırılabilme yüzdesi referans numuneye göre S10 kodlu karışım numunesinde \%13,05, S20 karışım numunesinde \%19,98 ve S30 karışım numunesinde $\% 33,30$ artmıştır.

Puzolanik reaksiyonun çimentonun hidratasyonuna kıyasla daha yavaş gerçekleşmesi, betonun sertleşme sürecini uzatmaktadır. Böylece yüksek fırın cürufu kullanımı, karışımlarda sıkıştırma sürecinin daha yavaş gerçekleştirilebilmesine olanak tanımaktadır. Deneylerde kullanılan yüksek fırın cürufunun inceliği, çimentoya kıyasla daha düşüktür. Bu da su ihtiyacını azaltarak işlenebilirliğe ve sıkıştırılabilme yüzdesine olumlu yönde katkı sağlamaktadır. 
Karimpour (2010), yapmış olduğu çalışmada, SSB karışımındaki yüksek fırın cürufu miktarını arttırmış, böylece karıştırma ve sıkıştırma arasında geniş zaman aralığı olsa dahi yüksek basınç dayanımı değerlerine ulaşabilmiştir. Bu sonucu şu şekilde açıklamıştır: cüruf miktarı arttıkça aslında çimento tanecikleri arasındaki mesafe artar, çimento partikülleri arasındaki mesafenin artması kristal ağ oluşumunun gecikmesine neden olur. Bu gecikme, SSB ile çalışmak için daha fazla zaman sağlamak amaciyla kullanılabilir (Karimpour, 2010).

Silindirle sıkıştırılmış betonların birim hacim ağırlıkları Çizelge 6'da verilmiştir. Kuru ve doygun birim hacim ağırlık değerleri kıyaslandığında, yüksek fırın cürufu kullanılmayan S0 karışım kodlu SSB numunesinin en büyük birim hacim ağırlık değerlerine sahip olduğu görülmektedir. Karışımdaki yüksek fırın cürufu miktarı arttıkça SSB numunelerinin birim hacim değerlerinde azalma olduğu belirlenmiştir. En yüksek azalma miktarı, yüksek fırın cürufu kullanılmayan S0 kodlu karışıma kıyasla, ağırlıkça \%30 oranında cüruf kullanılan S30 kodlu karışımda, kuru ve doygun birim hacim ağırlık değerinde yaklaşık $\% 2$ olarak tespit edilmiştir. Birim hacim ağırlık değerleri, malzemeyi oluşturan bileşenlerden ve malzemenin porozitesinden etkilendiği gibi, su emme yüzdelerinden de etkilenmektedir.

Çizelge 6. Birim hacim ağırlık

Table 6. Unit weight

\begin{tabular}{|c|c|c|}
\hline Karışım kodu & $\begin{array}{l}\text { Kuru birim hacim ağırlık } \\
\left(\mathrm{g} / \mathrm{cm}^{3}\right)\end{array}$ & $\begin{array}{l}\text { Doygun birim hacim ağırlık } \\
\left(\mathrm{g} / \mathrm{cm}^{3}\right)\end{array}$ \\
\hline S0 & 2,35 & 2,53 \\
\hline S10 & 2,34 & 2,50 \\
\hline S20 & 2,31 & 2,49 \\
\hline S30 & 2,30 & 2,48 \\
\hline
\end{tabular}

Birim hacim ağırlık deneylerinde değişken sadece yüksek fırın cürufu olduğundan, cürufun özgül ağırlığının çimentoya göre düşük oluşu sonuçlar üzerinde etkili olmuştur.

Silindirle sıkıştırılmış beton numunelerinin su emme yüzdeleri Çizelge 7 'de verilmiştir. Üretilen silindirle sıkıştırılmış betonların su emme yüzdeleri birbirine yakın değerler almıştır. Yüksek fırın cürufu kullanımını arttıkça, SSB numunelerinin su emme yüzdelerinde az miktarda dahi olsa azalma meydana gelmiştir. Su emme yüzdelerindeki azalma miktarları, S0 kodlu karışıma kıyasla S10, S20 ve S30 kodlu karışımlarda sırasıyla \%0,5, \%1 ve \%1,4 olarak belirlenmiştir. Yüksek fırın cürufu kullanımının SSB örneklerinde sıkıştırılabilme yüzdesini arttırması, su emme yüzdelerinde azalmaya neden olmuştur.

Aghaeipour ve Madhkhan (2017), yapmış oldukları çalışmada, SSB karışımlarında kullandıkları yüksek fırın cürufu miktarı arttıkça, su emme yüzdelerinin azaldığını tespit etmişlerdir; elde edilen neticeler, bu çalışmada elde edilen sonucu destekler niteliktedir.

Çizelge 7. Su emme yüzdesi.

Table 7. Water absorption

\begin{tabular}{cc}
\hline Karışım kodu & Su emme (\%) \\
\hline S0 & 6,37 \\
S10 & 6,36 \\
S20 & 6,30 \\
S30 & 6,28 \\
\hline
\end{tabular}

Ultrases geçiş hızının ölçülmesi, tahribatsız bir deney yöntemi olup ölçüm yapılan nokta, karışımda kullanılan malzemenin özellikleri, betonun boşluk yapısı, ölçüm yapılan malzemenin nem içeriği ve sıkıştırma yönü gibi parametrelerden etkilenebilmektedir. Ultrases geçiş hızı, betondaki boşluk miktarı ile doğrudan ilişkilidir. Betondaki boşluk miktarı artıkça, ultrases geçiş hızı azalmaktadır. Betonun basınç dayanımı da boşluk oranından etkilendiğinden, betona zarar vermeden basınç dayanımı hakkında fikir sahibi olabilmek açısından ultrases geçiş hızının belirlenmesi yarar sağlamaktadır. 
Silindirle sıkıştırılmış 28 günlük yüzey kuru suya doygun durumdaki betonların ultrases geçiş hızı ve dinamik elastisite modülü değerleri Çizelge 8 'de verilmiştir.

Çizelge 8. Ultrases geçiş hızı ve dinamik elastisite modülü

Table 8. Ultrasonic pulse velocity and dynamic modulus of elasticity

\begin{tabular}{ccc}
\hline Karışım kodu & $\begin{array}{c}\text { Ultrases geçiş hızı } \\
\text { (km/s) }\end{array}$ & $\begin{array}{c}\text { Dinamik elastisite modülü } \\
\text { (GPa) }\end{array}$ \\
\hline S0 & 4,62 & 34,70 \\
S10 & 4,70 & 39,09 \\
S20 & 4,65 & 35,83 \\
S30 & 4,63 & 35,21 \\
\hline
\end{tabular}

Çizelge 8 incelendiğinde, ultrases geçiş hızı ve dinamik elastisite modülü değerlerinin, cüruf kullanılmayan S0 kodlu karışıma kıyasla \%10, \%20 ve \%30 oranlarında cüruf kullanılan S10, S20 ve S30 kodlu karışımlarda yükseldiği görülmektedir. Cüruf kullanılan S10, S20 ve S30 kodlu karışımlar kendi içerisinde değerlendirildiğinde, karışımlardaki cüruf oranı arttıkça, ultrases geçiş hızı değerlerinde ve dinamik elastisite modülü değerlerinde azalma meydana gelmiştir.

S0 kodlu karışıma kıyasla S10, S20 ve S30 kodlu cüruf kullanılan karışımlarda, ultrases geçiş hızı değerleri sırasıyla $\% 1,7, \% 0,64$ ve $\% 0,21$, dinamik elastisite modülü değerleri ise sırasıyla $\% 12,65, \% 3,25$ ve $\% 1,47$ oranlarında artmıştır.

Standart küp SSB numunelerin 3 ve 28 günlük basınç dayanımları Çizelge 9'da verilmiştir. Yüksek fırın cürufu kullanımıyla referans numuneye göre erken yaş dayanımlarında azalma meydana gelirken, ilerleyen yaş dayanımlarında artma gerçekleşmiştir. Bu sonucun elde edilmesinde puzolanik reaksiyonun çimentonun hidratasyonuna göre yavaş gerçekleşen bir reaksiyon olmasının etkisi bulunmaktadır. Sıkıştırma işlemi sonunda betonlardaki hava boşluğu miktarının ve betonun porozitesinin de dayanım sonuçları üzerinde etkili olduğu düşünülmektedir.

Çizelge 9.3 ve 28 günlük basınç dayanımları (MPa)

Table 9. Compressive strengths at the ages of 3 and 28 days (MPa)

\begin{tabular}{ccc} 
Karışım kodu & 3 günlük & 28 günlük \\
\hline S0 & 34,1 & 39,9 \\
S10 & 31,9 & 43,5 \\
S20 & 27,3 & 43,3 \\
S30 & 26,8 & 42,4 \\
\hline
\end{tabular}

Cüruf kullanılan karışımlar kendi içerisinde değerlendirildiğinde, karışımlardaki cüruf oranı arttıkça dayanım değerlerinde azalma meydana gelmiştir. Cüruf kullanılmayan S0 kodlu karışıma kıyasla S10, S20 ve S30 kodlu cüruf kullanılan karışımlarda, 3 günlük basınç dayanımı değerleri sırasıyla $\% 6,45, \% 19,94$ ve $\% 21,41$ oranlarında azalmış, 28 günlük basınç dayanımı değerleri ise sırasıyla \%9, \%8,5 ve \%6,2 oranlarında artmıştır.

\%10 cüruf kullanımıyla, referans betona göre sıkıştırılabilme yüzdesi ve işlenebilirlik artmış, boşluk miktarı azalmıştır. Bu durum, betonun mekanik özelliklerini iyileştirmiştir. Öte yandan cüruf miktarı $\% 10$ 'dan daha fazla arttırıldığında, çimento dozajının azalması bu iyileşmenin önüne geçmiş, beton basınç dayanımı, boşluk oranı ve dinamik elastisite modülü gibi özellikler olumsuz yönde etkilenmeye başlamıştır.

Aghaeipour ve Madhkhan (2017), silindirle sıkıştırılmış betonlarda \%0, 20, 40 ve 60 oranlarında yüksek fırın cürufu kullanarak yapmış oldukları çalışmada, 28 günlük beton basınç dayanımlarında en yüksek değeri \%40 yüksek fırın cürufu kullanımıyla elde etmişlerdir. Bu çalışmada ise en yüksek 28 günlük basınç dayanımı değerleri, \%10 cüruf kullanımıyla elde edilmiştir, karışım tasarımının ve kullanılan malzeme özelliklerinin sonuçlar üzerinde etkili olduğu söylenebilir. 


\section{SONUÇ (CONCLUSION)}

Deneysel çalışmadan elde edilen veriler doğrultusunda aşağıdaki sonuçlara ulaşılmıştır:

- Yüksek fırın cürufu kullanımıyla işlenebilirlik olumlu yönde etkilenmiştir. Sıkıştırılabilme yüzdesi ağırlıkça \%10, \%20 ve \%30 oranlarında cüruf kullanılan karışımlarda, referans numuneye göre sırasıyla $\% 13,05, \% 19,98$ ve $\% 33,30$ oranlarında artmıştır.

- Yüksek fırın cürufu kullanılması, SSB numunelerinin birim hacim ağırlık ve su emme değerlerinde azalmaya neden olmuştur.

- Ultrases geçiş hızı ve dinamik elastisite modülü değerleri cüruf kullanımı ile artmıştır. Karışımdaki cüruf oranı arttıkça, ultrases geçiş hızı ve dinamik elastisite modülü değerlerindeki artış miktarında azalma meydana gelmiştir.

- Yüksek fırın cürufu ikamesi erken yaş beton basınç dayanımlarında azalmaya neden olurken ilerleyen yaş basınç dayanımlarında artış sağlamıştır. Cüruf kullanılan karışımlar kendi içerisinde değerlendirildiğinde, karışımdaki cüruf oranı arttıkça dayanım değerlerinde azalma meydana geldiği görülmüş̧ür.

- Bu çalışmadan elde edilen sonuçlara göre, 28 günlük beton basınç dayanımlarında en yüksek değerler \%10 yüksek fırın cürufu ikamesiyle elde edilmiştir. Yüksek fırın cürufu katkılı karışımlar arasında, en yüksek 3 günlük beton basınç dayanımı, yine \%10 cüruf içeren numunelerde görülmüştür.

\section{KAYNAKLAR (REFERENCES)}

Aghaeipour, A., Madhkhan, M., 2017, "Effect of ground granulated blast furnace slag (GGBFS) on RCCP durability", Construction and Building Materials, Cilt 141, ss. 533-541. https://doi.org/10.1016/j.conbuildmat.2017.03.019.

Albuquerque, M. C. F., Balbo, J. T., Sansone, E. C., Pinto, P. C., 2011, “Fracture characterization of roller compacted concrete mixtures with blast furnace slag and industrial sand", International Journal of Pavement Research and Technology, Cilt 4, Sayı 4, ss. 244-251. https://doi.org/10.6135/ijprt.org.tw/2011.4(4).244

ASTM C597-16, 2016, "Standard test method for pulse velocity through concrete", ASTM International, West Conshohocken, PA.

ASTM C1435/1435M-20, 2020, "Standard practice for molding roller-compacted concrete in cylinder molds using a vibrating hammer", American Society for Testing and Materials, ASTM International, USA.

BSI, 2011, "Methods of test for masonry units part 11: Determination of water absorption of aggregate concrete, autoclaved aerated concrete, manufactured stone and natural stone masonry units due to capillary action and the initial rate of water absorption of clay masonry units (EN 772-11)", BSI Stand. Publ., London, UK.

Chhorn, C., Lee, S. W., 2017, “Consistency control of roller-compacted concrete for pavement", KSCE J Civ Eng, Say1 21, ss. 1757-1763. https://doi.org/10.1007/s12205-016-0820-y

Dareyni, M., Mohammadzadeh Moghaddam, A., Delarami, A., 2018, “Effect of cationic asphalt emulsion as an admixture on transport properties of roller-compacted concrete", Construction and Building Materials, Sayı 163, ss. 724-733. https://doi.org/10.1016/j.conbuildmat.2017.12.156

Engin, Y., Gökalp, İ., Önkol, E., Ağaç, H., Ekim, H., 2019, “Türkiye'de silindirle sıkıştırılmış beton yol uygulamaları", Hazır Beton, Eylül-Ekim 2019, ss. 69-75.

Harrington, D., Abdo, F., Adaska, W., Hazaree, C. V., Ceylan, H., Bektas, F., 2010, “Guide for rollercompacted concrete pavements".

Hashemi, M., Shafigh, P., Asadi, I., Mahpour, A., Samadian, A., 2020, "The effect of superplasticizer admixture on the engineering characteristics of roller-compacted concrete pavement", International Journal of Pavement Engineering, ss. 1-16. https://doi.org/10.1080/10298436.2020.1858483 
Hazaree, C. V., 2010, “Workability and strength attributes of RCC: Effects of different chemical admixtures and resulting paste", Graduate Theses and Dissertations, 11250. https://lib.dr.iastate.edu/etd/11250

Hazaree, C. V., Ceylan, H., Taylor, P, Gopalakrishnan, K., Wang, K., Bektas, F., 2013, “Use of Chemical Admixtures in Roller-Compacted Concrete for Pavements", In Trans Project Reports, 57. https://lib.dr.iastate.edu/intrans_reports/57

Karimpour, A., 2010, "Effect of time span between mixing and compacting on roller compacted concrete (RCC) containing ground granulated blast furnace slag (GGBFS)", Construction and Building Materials, Cilt 24, Sayı 11, ss. 2079-2083. https://doi.org/10.1016/j.conbuildmat.2010.04.054

KGM, 2016, "Beton Yollar Teknik Şartnamesi", Karayolları Genel Müdürlüğü, Ankara.

Kılıç, İ., Gök, S. G., 2021a, "Silindirle sıkıştırılmış betonlarda su çimento oranının etkileri", Dicle Üniversitesi Fen Bilimleri Enstitüsü Dergisi (Dicle University Journal of Institute of Natural and Applied Science), Cilt 10, Sayı 1, ss. 73-84.

Kılıç, İ., Gök, S. G., 2021b, “A study on investigating the properties of alkali-activated roller compacted concretes", Advances in Concrete Construction, Cilt 12, Say1 2, ss. 117-123. http://dx.doi.org/10.12989/acc.2021.12.2.117

Kılıç, İ., Gök, S. G., 2021c, "Strength and durability of roller compacted concrete with different types and addition rates of polypropylene fibers", Revista de La Construcción, Cilt 20, Sayı 2, ss. 205-214. https://doi.org/10.7764/RDLC.20.2.205

Mardani, A., Bayqra, S. H., Özen, S., Faqiri, Z. A., Ramyar, K., 2020, "Silindirle sıkıştırılmış beton karışımlarında kullanılan malzemelerin özellikleri", Uluslararası Mühendislik Araştırma ve Geliştirme Dergisi, Cilt 12, Sayı 1, ss. 61-72.

Modarres, A., Hosseini, Z., 2014, “Mechanical properties of roller compacted concrete containing rice husk ash with original and recycled asphalt pavement material", Materials and Design, Say1 64, ss. 227236. https://doi.org/10.1016/j.matdes.2014.07.072

Pektaş, M. R, 2015, “Silindirle sıkıştırılabilen yol betonlarının kalıcılık özellikleri”, Yüksek Lisans Tezi, Anadolu Üniversitesi-Bilecik Şeyh Edebali Üniversitesi, Bilecik, Türkiye.

Shen, L., Li, Q., Ge, W., Xu, S., 2020, "The mechanical property and frost resistance of roller compacted concrete by mixing silica fume and limestone powder: Experimental study", Construction and Building Materials, Say1 239, 117882. https://doi.org/10.1016/j.conbuildmat.2019.117882

Şengün, E., Aykutlu, M. A., Yaman, İ. Ö., 2017, "Silindirle sıkıştırılmış beton yollar üzerine güncel bir tarama - bölüm 1: Özellikleri ve karışım tasarımı", Çimento ve Beton Dünyası, Sayı 120, KasımAralık 2017, ss. 93-114.

TÇMB, 2018, "Silindirle sıkıştırılmış beton yollar teknik şartnamesi", Ankara.

Topçu, İ. B., 2013, "High-volume ground granulated blast furnace slag (GGBFS) concrete", in Eco-Efficient Concrete, Woodhead Publishing Series in Civil and Structural Engineering, ss. 218-240. https://doi.org/10.1533/9780857098993.2.218

TS 802, 2016, "Beton karışım tasarımı hesap esasları", Türk Standartları Enstitüsü, Ankara.

TS EN 933-1, 2012, “Agregaların geometrik özellikleri için deneyler-Bölüm 1: Tane büyüklüğü dağılımının tayini-Eleme yöntemi", Türk Standartları Enstitüsü, Ankara.

TS EN 1097-6, 2013, “Agregaların mekanik ve fiziksel özellikleri için deneyler - Bölüm 6: Tane yoğunluğu ve su emme oranının tayini", Türk Standartları Enstitüsü, Ankara.

TS EN 12350-2, 2019, "Beton-Taze beton deneyleri-Bölüm 2: Çökme (slump) deneyi”, Türk Standartları Enstitüsü, Ankara.

TS EN 12390-3, 2019, “Beton-Sertleşmiş beton deneyleri-Bölüm 3: Sertleşmiş beton deney numunelerinde basınç dayanımının tayini", Türk Standartları Enstitüsü, Ankara.

TS EN 15167-1, 2006, “Öğütülmüş yüksek fırın cürufu-Beton, harç ve şerbette kullanım için-Bölüm 1: Tarifler, özellikler ve uygunluk kriterleri", Türk Standartları Enstitüsü, Ankara.

Url-1, http://www.tracim.com.tr/?sayfa=urunler, ziyaret tarihi: 08 Eylül 2021.

Url-2, http://www.bolucimento.com.tr/documents/bolu-ogutulmus-yuksek-firin-curufle.html, ziyaret tarihi: 10 Temmuz 2021. 
Yazıcı, Ş., 2008, "Silindirle sıkıştırılmış beton (SSB)". https://www.imo.org.tr/resimler/ekutuphane/pdf/14954.pdf

Yetim, E., Yılmaz, D., 2019, “Beton yollar ve silindirle sıkıştırılmış betonun Türkiye'deki yeni uygulama alanı". $\quad$ https://webdosya.csb.gov.tr/db/yfk/icerikler/makale---beton-yollar-9-eylul-201920191220130448.pdf 